\title{
UPACARA ADAT PERKAWINAN BENGKULU (Analisis Filosofis, Nilai Islam dan Kearifan Lokal)
}

\author{
Samsudin \\ Dosen IAIN Bengkulu \\ Email: samsudin@iainbengkulu.ac.id
}

\begin{abstract}
The philosophical values contained in the building of the traditional marriage of the Malay community of the City of Bengkulu are a reflection of the socio-cultural relations of Malayness with Islamic values. Historically, Bengkulu Malay Islam was an incarnation of acculturation and assimilation between Muslims who came to Bengkulu. The position of the process of acculturation of Islam in Bengkulu Malay society, became very significant as the basis of the cultural process of Bengkulu society until now. Acculturation of values and internalization of Islamic values is very functional in shaping philosophical values in the custom of marriage of the Bengkulu community. This is expressed in every stage of the traditional marriage, there are ritual processions that are inter-related with local wisdom, Islamic values and other Islamic philosophical meanings.

Keywords: Customary marriage, acculturation, Islamic values, local wisdom
\end{abstract}

Abstrak: Nilai-nilai filosofis yang terdapat dalam bangunan adat perkawinan masyarakat Melayu Kota Bengkulu merupakan cerminan dari relasi sosial budaya kemelayuan dengan nilai-nilai Islam. Secara historis, Islam melayu Bengkulu merupakan penjelmaan akulturasi dan asimilasi antara Islam yang datang ke Bengkulu.Kedudukan proses akulturasi Islam dalam masyarakat Melayu Bengkulu, menjadi sangat signifikan sebagai dasar proses kebudayaan masyarakat Bengkulu hingga sekarang. Akulturasi nilai dan internalisasi nilai-nilai Islam sangat fungsional dalam membentuk nilai filosofis dalam adat perkawinan Masyarakat Bengkulu. Hal ini terekspresi dalam setiap tahapan adat perkawinan terdapat prosesi ritual yang Inter-related dengankearifan lokal, nilai Islam dan makna filosofis Islami lainnya.

Kata kunci : Adat perkawinan, akulturasi, nilai Islam, kearifan lokal.

\section{Pendahuluan}

Setiap komunitas atau etnis masyarakat memiliki adat istiadat yang dilaksanakan dalam hajat tertentu secara kolektif. Upacara adat merupakan ritual formal maupun non formal dengan pola kesepakatan bersama dan dilaksanakan secara fungsional. Upacara adat berfungsi, bukan saja sebagai identitas sosial satu komunitas, tetapi telah menjadi dasar dan cermin pandangan hidup masyarakat yang bersangkutan. Karenanya upacara adat biasanya sarat dengan nilai-nilai filosofis.

Nilai-nilai filosofis yang terbangun dan menjelma dalam konstruk bangunan adat perkawinan masyarakat (Melayu) Kota Bengkulu merupakan cerminan dari relasi sosial dan budayakemelayu- an. Meski sudah berjalan sekian lamamempertahankan nilai-nilai, baik sosial, budaya maupun filosofis, hingga saat ini masih kuat.Karena upacara adat perkawinan tersebut masih relevan dengan perkembangan jaman, dan justru fungsional sebagai kontrol moral bagi masyarakat Bengkulu.

Ada beberapa alasan kuat bagi masyarakat yang masih menjunjung tinggi adat perkawinan tersebut, di antaranya adalah simbolisitas masyarakat beradat dan beradab, nilai-nilai filosofis ajaran Islam, kemasyarakatan, keindahan, adat istiadat, seni budaya, pendidikan, dan hukum, yang semuanya sebagai reduktor dari masyarakat secara umum. Hal tersebut tidak dapat dilepaskan dengan sejarah akumulasi nilai-nilai tersebut. Sejarah sosial buda- 
86

ind

NUANSA Vol. XI, No. 2, Desember 2018

ya aspek filosofis adat perkawinan menjadi bagian penting dalam upaya mempertahankannya dalam wujud kehidupan.

Pertanyaan yang muncul atas fenomena tersebut adalah mengapa upacara adat perkawinan tersebut masih dipertahankan? Ada beberapa perspektif untuk menjelaskannya, di antaranya kekuatan sejarah nilai-nilai filosofis yang masih fungsional hingga saat ini. Sehubungan dengan permasalahan tersebut, tulisan ini akan menjelaskan hal-hal tersebut dalam perspektif sejarah sosial nilai-nilai filosofis yang terkandung dalam upacara adat perkawinan Bengkulu. Tulisan ini merupakan ringkasan hasil penelitian dan telah direvisi dengan data baru melalui survey dan wawancara.

\section{Prosesi Upacara Adat Perkawinan}

Pranata perkawinan adalah pranata formal yang secara tertulis atau tidak tertulis memiliki prosedur dinamis, baik lengkap maupun sederhana dan menjadi penuntun masyarakat bagi kegiatan tertentu. Misalnya pranata nonformal pencarian jodoh oleh seorang bujang atau gadis(bemete). Bila anak remaja telah bemete secara serius, selanjutnya ditandai kesepakatan untuk menyatakan keseriusannya kepada masing-masing orang tua, atau bahkan juga disampaikan kepada pihak orang tua asing-masing.Dari sini dimulailah kegiatan adat upacara perkawinan dimulai. ${ }^{1}$

Malam Berasan. Malam berasan yaitu malam musyawarah mufakat yang dilakukan oleh keluarga yang akan berhajat mengawinkan anak gadis/bujangnya. Berasan terdiri atas penghulu adat, penghulu agama, cerdik cendikia, tokoh masyarakat, jiran tetanggo serta sanak famili. Malam berasan bertujuan untuk menetapkan TuoKerjo(ketua kerja atau panitia), Tuo Sambal (kordinator masak gulai), TuoJuada(ketua kue-kue), Tuo Jenang(ketua penghidangan), TuoKanca (tukang masak air dan nasi), Tuo Sirih(ketua penyiapan sirih pinang adat cerano), dan TuoImbau (tukang panggil).

Beberapa hari kemudian atau paling lama satu minggu, dilanjutkan acara merempah dan me-

'Meski di Kota Bengkulu terdapat etnik pribumi kolektif Melayu, Bulang dan Lembak - yang semuanya berbasis muslim, - namun tradisi adat perkawinan sudah melembaga dan menjadi upacara adat yang sudah dilaksanakan secara bergenerasi, bahkan sampai sekarang sebahagian masyarakat ketiga komunitas tersebut masih melaksanakan.
S amsudin | Upacara Adat Perkawinan Bengkulu 86

\section{6}

mecah juada atau menegak penghujung atau taruf atau tenda. Dalam acara ini juga dilaksanakan menghias rumah dengan memasang pelaminan pengantin dan dekorasi.

Keesokan harinya dilanjutkan dengan acara PengantenBetange. Adalah calon mempelai wanita menjalani mandi harum serta luluran keharuman. Prosesi ini dilaksanakan setelah waktu Isya dihadiri oleh kerabat dekat dan jiran tetanggo. Keesokan harinya dilanjutkan acara ziarah kubur yang dilakukan oleh penganten perempuan ke kuburan para leluhur. Calon penganten perempuan didampingi oleh keluarga, Induk Inang dan Imam (Masjid setempat) sebagai penanggungjawab kegiatan.

Pada hari yang sama, setelah ziarah kubur, dilanjutkan acara Bedabung. Dimana calon mempelai perempuan melakukan kikir gigi yang diiringi oleh musik adat berupa gendang serunai, dilengkapi oleh hidangan khas rujak serta nasi kunyit. Calon mempelai berbusana adat berupa kebaya penganten dengan hiasan sanggul sikek.

Pada malam harinya diadakan acara malam bainai. Pada malam acara ini calon mempelai perempuan naik bainai, yakni kegiatan memerahkan kuku (memberi warna pada kuku) dengan menggunakan gilingan daun pacar (inai) dan dipandu oleh pengasuh induk inang dan anak-anak gadis kawan sejawatpenganten perempuan. Penanggungjawab kegiatan ini adalah Induk Inang.

Keesokan pagi harinya adalah menerima belanjo (Tunangan Adat) dan akad nikah. Menerima belanjo (menerima uang antaran) seserahan dan mas kawin dari pihak keluargo calon mempelai laki-laki, kedua calon pengantin duduk bertunangan dan sekaligus pelaksanaan prosesi uang naik kerjo jadi. Setelah itu dilanjutkan proses akad nikah.

Dalam akad nikah, calon penganten laki-laki mengambil tempat di majelis akad nikah di depan susunan sirih cerano dengan duduk mengangkek (mengangkat) sembah sujud kepada calon mertuo dengan ucapan "mohon sayo dinikahkan kepado anak Bapak yang bernamo ..... binti ....... Kemudian urangtuo calon penganten perempuan menjawab "Ya Insya-Allah".Dalam Prosesi akad nikah, calon penganten perempuan berbusana penganten adat lengkap.

Becampur, pada hari yang sama setelah menikah melalui rangkaian hadang galah oleh tuokerjo, hadang kain oleh tuo sambal, dan hadang ki- 
87 愈

NUANSA Vol. XI, No. 2, Desember 2018

pas oleh induk inang di pelaminan dengan saling berbalas pantun, menggunakan bahasa kias ibarat simbol kerjo beradat. Sedangkan kedua penganten mengenakan busana penganten adat lengkap.

Mufakat Rajo Penghulu, dilaksanakan pada hari yang sama sore hari. Dalam mufakat rajo penghulu, tuokerjo dengan menghadap nenek mamak minta restu dan petunjuk suluh untuk berjalan di tempek (tempat) kelam, tungkek (tongkat) untuk mendaki bukit dan lurah untuk menemui kampung. Rajo penghulu, ditemani limoberadik (sirih cerano) datang menghadap dan mengangkat sembah sirih cerano jalan di muko kepada rajo penghulu (Ketuo Adat) untuk meminjam adat peradatbimbang rajo yang dirajokan.

Dalam tradisi masyarakat Bengkulu, adat bimbang dapat dipinjamkan setelah memenuhi beberapa ketentuan rajo penghulu setelah berjanji memenuhi syarat tertentu dan ditandai bunyi tabuh gendang serunai, serto memecah nasi, setelah siang hadirin turun dari penghujung dan melaksanakan acara bedampeng / berendai pencak silat asli Bengkulu.

Selanjutnya kegiatan Belarak, dilaksanakan pada hari yang sama. Belarak merupakan prosesi dimana penganten lelaki dan perempuan diarak dengan kendaraan tertentu yang dipandu oleh Induk Inang dan TuoKerjo yang diikutsertakan oleh seluruh sanak famili penganten yang diiringi bunyi serunai. Biasanya dilaksanakan setelah waktu salat Ashar.

Upacara mandi-mandi. Acara mandi-mandi penganten adalah kedua penganten melakukan prosesi siraman diiringi dengan bunyi gendang serunai dan puncak pedang yang dipimpin oleh Induk Inang dan Tuokerjo. Mempelai dimandikan oleh pihak keluargo masing-masing. Perlengkapan mandi disediakan oleh lembaga adat, saat ini biasanya perlengkapan adat sudah langsung disiapkan oleh pihak salon, dibalut dengan kain besurek dengan menggunakan sunting adat lengkap. Penanggungjawab acara ini biasanya adalah Induk Inang, TuoKerjo dan Tuo Sirih.

Bedendang. Bedendang dilaksanakan pada malam harinya. Adalah acara kesenian yang diiringi oleh alunan musik biola dan tepuk tari sorak sorai kesenian asli Bengkulu. Kegiatan ini diawali dengan tari Bedampeng/berendai sampai dengan tari kain. Mutus tari dilakukan oleh mempelai laki-laki.
S amsudin I Upacara Adat Perkawinan Bengkulu

Selanjutnya acara BerdzikirSyarofalAnam. Acara ini dilaksanakan pada keesokan harinya. BerdzikirSyarofalAnam adalah musik Islami tradisional asli Bengkulu dengan menggunakan gendang besar (diameter $40 \mathrm{~cm}$ ) berjumlah antara 25-30 personil, dengan irama khas mengiringi bacaandzikiryang diambil dari kitab Albarjanzi. Kemudian dilanjutkan dengan tamat kaji (khotam Quran) yang akan dilakukan oleh kedua mempelai, dan akan duduk dan membaca Alquran didampingi oleh kedua orang tuanya. Penangungjawab kegiatan ini adalah Imam Masjid.

Menjamu di rumah (resepsi rumah), dilaksanakan setalah selesai berdzikir. Hidangan masakan rumah, di bawah pimpinan Tuo Sambal. Pada acara ini biasanya dihibur oleh musik tradisional seperti rebana. Busana orangtua penganten,yang perempuan mengenakan kebaya dan kain batik, orang tua laki-laki mengenakan Jas lengkap berkopyah/peci. Sedangkan keluarga, wanita berkebaya/gamis, pria menegenakann Jas atau Batik.

Malam Begamat (malam hiburan dengan musik Gambus) yang dilaksanakan pada malam harinya. Malam begamat adalah malam hiburan yang menampilkan kesenian Melayu Asli dari Kota Bengkulu. Pengantin dan pihak keluarga ikut menyumbangkan lagu lagu, dan biasanya harus lagu-lagu melayu asli.

Resepsi. Acara resepsi adalah peresmian pernikahan yang biasa dilaksanakan di rumah atau di gedung dengan hiburan musik modern, diiringi tari persembahan lengkap dengan pencak silatnya. Pakaian penganten juga mengenakan famili, jiran tetanggo dan handai taulan diundang untuk merayakan acara resepsi pernikahan.Resepsi adalah puncak dari rangkaian adat perkawinan yang dilaksanakan selama seminggu. Setelah itu biasanya ada acara pembubaran panitia dan ucapan terima kasih yang dilakukan oleh pihak keluarga yang punya hajat bertempat di rumahnya sekaligus makan malam pada hari yang sama.

\section{Nilai-nilai Filosofis}

Menikah adalah perintah agama. Meski demikian, dalam pelaksanaannya upacara budaya tidak lepas dari ekspresi jiwa manusia. Akulturasi agama dan budaya dalam upacara adat perkawinan, terdapat kekuatan nilai-nilai Islam (islamicsvalues), kemasyarakatan (socialvalues), tradisi-tradisi adat 
(customvalues), kesenian (estetis values), hukum (lowvalues), pendidikan (educationvalues). dan sistem kekerabatan (familys norm).Nilai-nilai filosofis tersebut nampak dari mayoritas semua tahapan dalam upacara adat perkawinan Bengkulu.

Malam Berasan. Adalah musyawarah untuk mufakat yang dilakukan oleh keluarga yang akan berhajat mengawinkan anak. Hal ini menunjukkan bahwa kehidupan bersama dalam bentuk saling membantu dalam menentukan hal-hal penting yang mengedepankan musyawarah, juga memberi penghargaan tinggi kepada sesepuh adat, sosial, agama, bahkan keterampilan tertentu yang dibutuhkan dalam kegiatan hajatan dimaksud. Di dalam tahapan ini terdapat nilai hukum adat masyarakat beradat.

Merempah dan memecah Juada. Menandai kegiatan masak-memasak yang dilakukan oleh orang-orang di bagian dapur yang dilakukan oleh tetua Juada dengan mengedepankan kebersamaan yang melibatkan sanak saudara dan jiran tetangga. Kebersamaan juga berbentuk adanya bantuan material dari orang lain untuk acara tersebut. Pada tahapan ini terdapat nilai kesederhanaan simbol kebutuhan ekonomi.

PengantenBetange. Berarti pengantin melakukan pemandian. Seorang calon pengantin diharuskan melakukan pembersihan dan pensucian raga dan jiwa. Bunga-bunga harum bermakna agar jiwa yang tercermin dari calon pengantin harus memberikan kebermanfaatan bagi diri, keluarga, tetangga dan masyarakat. Kesaksian kerabat dekat dalam kegiatan tersebut, memberi motivasi bagi kehidupan keluarga selanjutnya.

Ziarah kubur. Adalah bermaknamelakukan sunah rasul sebagai upaya memberi penghormatan dan mendoakan kepada arwah kerabat yang menjadi leluhur dan telah tiada. Hal ini bermakna mengingatkan bahwa hidup yang akan dijalani merupakan bagian dari upaya untuk menyiapkan diri menghadap Sang Khaliq. Pada tahapan ini terdapat nilai-nilai syari'at Islam.

Bedabung. Dimana calon mempelai perempuan melakukan kikir gigi, bermakna sebagai upaya mempercantik diri di bagian mulut. Mulut merupakan bagian anatomi tubuh yang banyak berbicara dalam setiap pekerjaan. Adalah simbol agar pengantin setelah menjalani kehidupan dalam rumah tangga dapat menjaga mulutnya dari yang mengakibatkan perselisihan dan akibat buruk lainnya. Ber- bicara dengan baik sesuai adat dan bermakna serta dapat membangun keharmonisan rumah tangga. Pada tahapan terdapat nilai-nilai seni kehidupan dan berbahasa bernuansa jiwa beradat.

Malam Bainai. Adalah memerahkan kuku (memperindah tangan yang digunakan bersalaman/ bershilaturrahmi dengan orang lain). Mewakili seluruh bagian anatomi tubuh yang sering bergerak, seperti kaki, dan lain-lain. Menjadi simbol bahwa setelah menjalani hidup berumah tangga agar pengantin dapat melakukan sesuatu keterampilan yang bermakna bagi keluarga dan berperilaku indah, sebagaimana perintah ajaran Islam. Nilai filosofis seni keterampilan bermakna lebih mendalam bagi hakikat berperilaku.

Tunangan Adat. Berarti menerima belanja atau antaran dari calon besan. Resminya bersatu keluarga besar calon kedua mempelai diawali sedeqah dengan saling memberi dan menerima dan saling menolong dan dapat dijalankan untuk kehidupan selanjutnya. Setelah kegiatan tersebut kemudian dilangsungkan akad nikah sesuai syari'ah Islam. Ada nilai kekerabatan yang akan terbangun pada salah satu model organisasi keluarga pada masyarakat Bengkulu.

Becampur. Saat kegiatan ini berlangsung, kedua mempelai telah sah menikah. Penganten akan bertemu dan duduk bersanding yang pertama setelah menikah. Meski sudah sah sebagai suami dan isteri, untuk bersanding pertama harus meminta izin dan restu kepada sesepuh dan kerabat. Ini juga bermakna bahwa para tetua harus tetap mendapat menghormatan dan ridho dari orang tua meski telah berumah tangga.Mufakat Rajo Penghulu, Ini merupakan adat mengunggulan adat atas kerja bersama dengan memberitahukan kepada orang-orang tertentu dimana saja berada.

Belarak. Adalah penganten diarak diiringi bunyi serunai. Simbol sosialisasi pengantin telah sah menikah kepada khalayak sosial dan agar dapat diterima dengan damai oleh anggota masyarakat dimana saja. Selanjutnya upacara mandi-mandipenganten melakukan prosesi siraman. Keduanya ini adalah simbol dari keharusan mandi wajib (dalam syari'at Islam bagi kedua suami misteri yang telah melakukan hubungan seksual). Kembali sebagai simbol bagi kesucian jiwa dan raga dihadapan Allah SWT dan keberkahan hidup secara syari'at dan kesalehan sosial. 


\section{Nilai-nilaiIslam dan Kearifan Lokal}

Sejalan dengan perkembangan adat istiadat dari abad ke abad, dengan masuknya Islam, maka adat dan kepercayaan agama Islam merupakan pengganti kepercayaan sebelumnya seperti animisme dan lain-lain. Sementara itu kebudayaan Melayu memberikan corak pula dalam perkembangan kebudayaan Bengkulu selanjutnya, termasuk upacara adat perkawinan.

Upacara adat perkawinan merupakan formalitas material dan non material yang mengandung kekuatan nilai Islam, kemasyarakatan, hukum adatistiadat, seni/keindahan, pendidikan, dan sistem kekeluargaan. Filosofi kehidupan masyarakat Bengkulu kental dengan nilai agama yang menjadi dasar kehidupan sehari-hari.Setiap unsurnilai tersebut saling menguatkan dalam setiap tahapan upacara adat perkawinan tersebut. Bagaimana sejarah sistem kekuatan filosofis tersebut hingga koherensinya nilai-nilai tersebut pada upacara adat khususnya perkawinan masyarakat Bengkulu.

\section{Akulturasi Islam dan Lokal Genius}

Islam sebagai sebuah agama yang mempunyai klaim teologis sebagai agama dan bersifat universal, harus berhadapan dengan kebudayaan lokal dan temporal. Sepanjang sejarahnya, terlihat betapa Islam sebagai agama hadir dengan wujud artikulasi yang beragam, mulai dari mewarnai dengan memberi ruh Islam, mengolah dan mengubah, memperbaharui, dan dalam kasus-kasus tertentu, tidak jarang malah diwarnai oleh kebudayaan lokal. Dalam konteks ini, tampaknya Islam ingin menunjukkan dirinya sebagai suatu agama yang mempunyai padanganbudaya yang kosmopolit, sebuah padangan budaya yang konsep dasarnya meliputi, dan diambil dari budaya seluruh umat manusia. ${ }^{2}$ Dalam konteks ini pulalah adagium "al Islam shuthihlikulli zaman wa makan" (Islam sesuai segala zaman dan tempat) menjadi relevan dan teruji pada tingkat sosiologi.

Terdapat beberapa hal yang perlu dipertimbangkan dalam melihat masalah Islam dalam hubungannya dengan kebudayaan. Pertama, Islam selalu berdiri dalam posisinya sebagai agama yang berusaha untuk mengadakan dialog kultural dengan kebu-

${ }^{2}$ Hasan Mua'arifAmbary,Menemukan Peradaban: Jejak Arkeologis dan Historis Islam di Indonesia,(Jakarta : Logis, 1988), hlm. 252. dayaan yang melingkupinya, dengan tetap mengedapankan fungsinya sebagai pembentuk realitas dan landasan identitas bagi kebudayaan. Kedua,di lain pihak, dalam proses akulturasi Islam, lahir apa yang disebutlocal genius, yakni kemampuan menyerap sambil mengadakan seleksi dan pengolahan aktif terhadap pengaruh kebudayaan asing, sehingga dapat dicapai satu ciptaan baru yang unik dan tidak terdapat di wilayah bangsa yang membawa pengaruh budaya tersebut. Ketiga,sosialisasi dan adaptasi Islam dengan kebudayaan tidak bisa dilepaskan dari realisasi historis pada saat Islam disosialisasikan. Hasil identifikasi terhadap dasar legitimasi kultural dapat diterima Islam, termasuk proses dan strategi yang dikembangkan secara lokal.

Kerangka yang disebutkan terakhir, tampaknya juga berlaku untuk menjelaskan persentuhan Islam dengan kebudayaan lokal di Nusantara, termasuk persentuhannya dengan budaya Melayu Bengkulu. Sulit untuk dibantah bahwa Islam dalam wataknya yang universal telah menjadi nilai pembentuk dan landasanindentitas bagi budaya orang Melayu Bengkulu, sebagaimana sulitnya membantah terdapatnya localgeniusdan keterkaitan antara realitas historis dan strategi yang digu $\neg$ nakan dalam sosialisasi Islam Bengkulu dengan kebudayaan Melayu Bengkulu.

Dari teori di atas internalisasi Islam bagi orang Melayu Bengkulu sangat kuat dan mewarnai segala aktivitas hidup secara lokal. Meski sudah berabadabad lamanya, watak keislaman masyarakat Bengkulu sangat kuat mendasari dalam tradisi upacaraupacara untuk memenuhi hajat hidupnya, termasuk hajat perkawinan yang tertuang dalam upacara adat perkawinan hingga sekarang.

\section{Adat Besendi Syara' dan Kitabullah}

Masuknya Islam ke tanah Bengkulu menjadi sebuah ajaran agama baru bagi masyarakat Bengkulu. Ajaran Islam sangat bertolak belakang dengan sistem kepercayaan yang dianut sebelumnya. Islam adalah agama yang suci yang berasal dari Tuhan Yang Esa. Islam hadir mengikis sedikit demi sedikit sistem kepercayaan animisme dan dinamisme, menjadi keyakinan bertauhid kepada Allah yang Esa sebagai pencipta alam seisinya. Islam secara berangsur tapi pasti, akhirnya menjadi agama yang mayoritas dianut oleh masyarakat Bengkulu.

Secara umum, kebudayaan Melayu Bengkulu, 
90

広

NUANSA Vol. XI, No. 2, Desember 2018

mempu $\neg$ nyai ruh yang sama dengan kebudayaan Melayu luar Bengkulu. Halini bisa dimengerti karena konsepsi adat istiadat Melayu "Adat bersendikan hukum syara, syara' bersendikan Kitabullah", bisa dipastikan menjadi titik pembuhul kebudayaan Melayu pada umumnya. Dalam konteks ini tampaknya Islam memberi warna terhadap kebudayaan asli Beng $\neg$ kulu, dengan tetap mempertimbangkan kebudayaan aslinya. Oleh karena itu, penting untuk ditegaskan bahwa budaya Islam Melayu Bengkulu pada dasarnya merupakan refleksi dan sosialisasi Islam dan adaptasinya, seperti tampak pada aspek bahasa, kesenian upacara maupun tata lakunya. Hasil adaptasi ini merupakan apresiasi terhadap Islam sebagai kaidah normatif dan diartikulasikan dalam wujud kebudayaan lokal, bersamaan dengan Islam.

Ajaran Islam akhirnya mewarnai berbagai aspek kehidupan masyarakat Melayu Bengkulu. Berbagai kegiatan upacara adat istiadat telah diresapi nilainilai Islam, misalnya tradisi khitanan (sunatan), perkawinan, dan kematian. Dalam menjalankan kegiatan-kegiatan tersebut, di dalamnya juga terdapat rangkaian kegiatan ajaran Islam, misalnya do'a-do'a sebagai ungkapan syukur. Upacara tradisional ini dapat diadakan secara kolekktif, dengan mengumpulkan beberapa orang mengadakan sembahyang bersama, dan diiringi dengan doa syukur. Setelah itu diadakan makan bersama yang diadakan secara kolektif pula.

\section{Kesimpulan}

Dari uraian di atas, dapat disimpulkan bahwa nilai-nilai filosofis yang terdapat dalam bangunan adat perkawinan masyarakat Melayu Kota Bengkulu merupakan cerminan dari relasi sosial budaya ke-
S amsudin | Upacara Adat Perkawinan Bengkulu 90

melayuan dengan nilai-nilai Islam. Secara historis, Islam melayu Bengkulu merupakan penjelmaan akulturasi dan asimilasi antara Islam yang datang ke Bengkulu.

Upaya mempertahankan upacara adat perkawinan oleh masyarakat pendukungnya di Bengkulu, membuktikan tingginya nilai filosofis dalam rangkaian adat upacara perkawinan tersebut. Selain itu, nilai-nilai tersebut memiliki sejarah dalam kesatuan perjalanan terbentuknya nilai-nilai tersebut hingga sekarang. Beberapa sejarah penting terbentuknya nilai-nilai dalam upacara adat perkawinan di Bengkulu, di antaranya nilai-nilai Islam (islamicsvalues), kemasyarakatan (socialvalues), tradisi-tradisi adat (customvalues), kesenian (estetis values), hukum adat (lowvalues), pendidikan (adecationvalues). dan sistem kekerabatan (familys norma). Nilai-nilai filosofis dan nilai-nilai Islam tersebut terintegrasi dari mayoritas semua tahapan dalam upacara adat perkawinan masyrakat Melayu Bengkulu.

\section{Daftar Pustaka}

Departemen Pendidikan dan Kebudayaan, Sejarah Daerah Bengkulu, (Bengkulu: Pusat Penelitian Sejarah dan Budaya, 1978/1979),

Departemen Pendidikan dan Kebudayaan, Adat Istiadat Daerah Bengkulu, (Bengkulu: P3KD, 1977),

Hasan Mua'arifAmbary, Menemukan Peradaban: Jejak Arkeologis

dan Historis Islam di Indonesia, (Jakarta : Logis, 1988)

Sumber informan wawancara, Akmaluddin (tokoh adat) Kelurahan Pasar Bengkulu, Kecamatan Teluk Segara, Kota Bengkulu. 
畜

91 NUANSA Vol. XI, No. 2, Desember 2018 